\title{
Ticagrelor: An investigational oral antiplatelet treatment for reduction of major adverse cardiac events in patients with acute coronary syndrome
}

This article was published in the following Dove Press journal:

Vascular Health and Risk Management

19 October 2010

Number of times this article has been viewed

\section{Eitan Abergel \\ Eugenia Nikolsky}

Heart Institute, Rambam Health Care Campus and Technion-Israel Institute of Technology, Haifa, Israel
Correspondence: Eugenia Nikolsky Heart Institute, Rambam Health Care Campus, Technion-Israel Institute of Technology, Haifa, 31096, Israel

$\mathrm{Tel}+97248542$ I8I

Fax +97248543 45I

Email e_nikolsky@rambam.health.gov.il
Abstract: Acute coronary syndromes (ACS) are the leading cause of mortality and one of the main reasons for hospital admissions in the developed nations. Due to high rates of mortality and reinfarction, ACS represent a major public health concern. Platelets play a central role in atherothrombosis, the main pathologic substrate in ACS. Sufficient inhibition of platelet aggregation is therefore one of the key targets in the treatment of ACS. Blockade of the P2Y ${ }_{12}$ subtype of adenosine diphosphate (ADP) receptor on platelet cell membranes has been established as a key mechanism of platelet inhibition. Clopidogrel, an ADP receptor antagonist and a second-generation thienopyridine, has been demonstrated to be of clinical benefit in patients with ACS when added to aspirin. A delayed onset of action due to two-step conversion to the active metabolite, irreversible binding to $\mathrm{P} 2 \mathrm{Y}_{12}$ receptors, and broad interindividual variability in levels of platelet response are the main limitations of clopidogrel. Prasugrel, a novel thirdgeneration thienopyridine, provides faster and stronger inhibition of platelet aggregation than clopigodrel. However, like the active metabolite of clopidogrel, prasugrel binds irreversibly to the $\mathrm{P} 2 \mathrm{Y}_{12}$ ADP receptor site, causing inhibition of platelet aggregation for the life of the platelet. Although in a randomized, double-blind trial prasugrel demonstrated superiority for multiple cardiovascular endpoints compared with standard-dose clopidogrel, it was also associated with an increased bleeding risk, including fatal bleeding. This review discusses the optimal antiplatelet regimens for management of patients with ACS, with special focus on ticagrelor, the first oral agent in a new chemical class of nonthienopyridine antiplatelet agents termed cyclopentyltriazolo-pyrimidines. Faster and greater platelet inhibition than clopidogrel, quick recovery of platelet function, and high efficacy regardless of clopidogrel response status, are the obvious advantages of ticagrelor as compared with thienopyridines. The prospective, randomized Platelet Inhibition and Patient Outcomes trial has established the clinical utility, enhanced efficacy, and similar safety of ticagrelor as compared with clopidogrel in a wide range of patients with ACS managed with contemporary antithrombotic therapies and invasive strategies when indicated. Dyspnea, ventricular pauses $\geq 3$ seconds, and elevation of serum creatinine and uric acid are the most common known adverse effects associated with ticagrelor, and require further comprehensive assessment.

Keywords: ticagrelor, acute coronary syndrome, platelets, percutaneous coronary intervention

\section{Introduction}

Acute coronary syndromes (ACS) are the leading cause of mortality and one of the main reasons for hospital admissions in the developed nations. ${ }^{1}$ Improvement of outcomes in patients with ACS is therefore a major health care task.

Platelets play a central role in atherothrombosis, the main pathologic substrate in ACS. ${ }^{2,3}$ Several platelet membrane receptors (Figure 1) bind with extracellular factors 


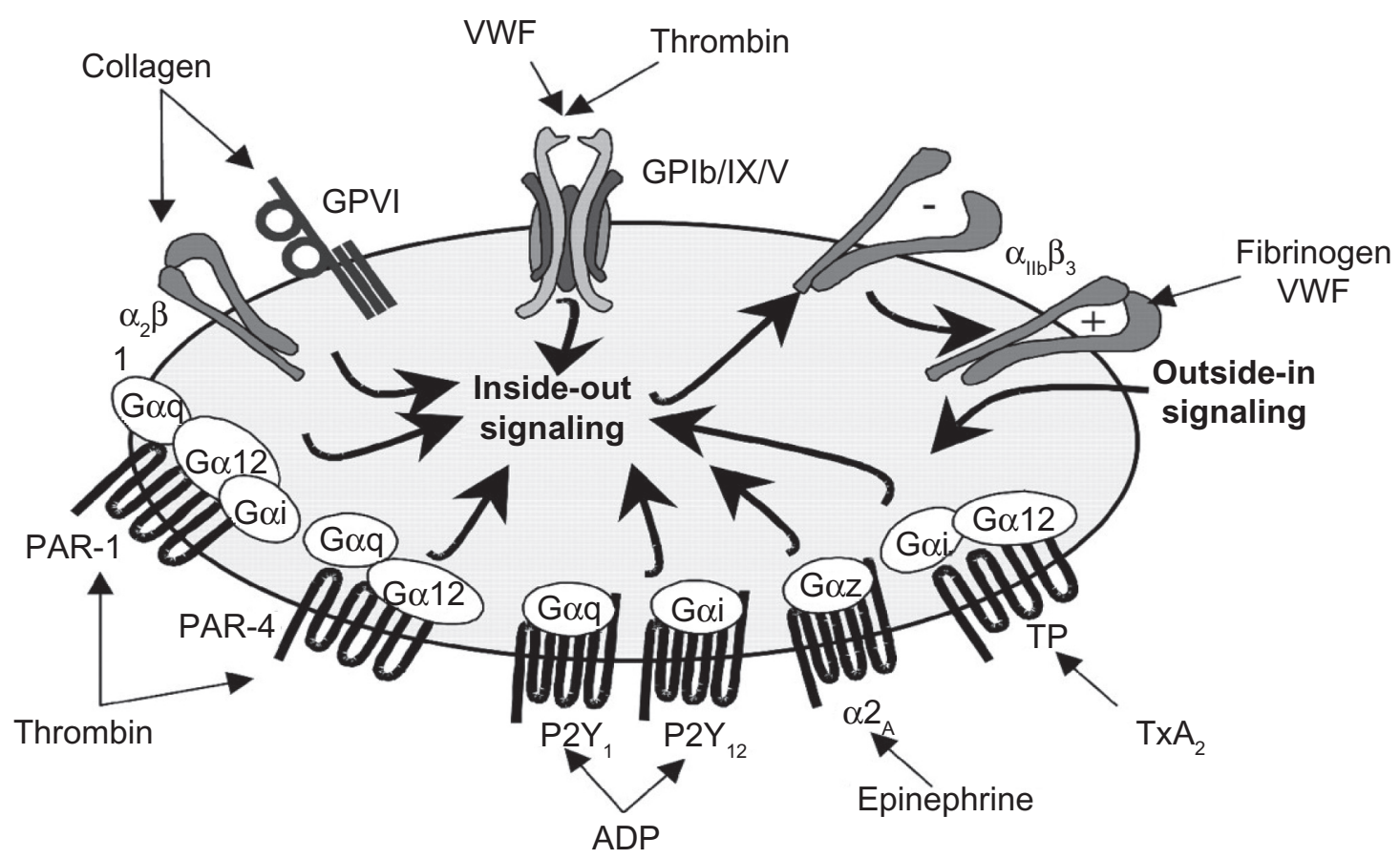

Figure I Schema of platelet receptor-ligand interactions. Copyright @ 2009. Adapted with permission from Rivera J, Lozano ML, Navarro-Núñez L, Vicente V. Platelet receptors and signaling in the dynamics of thrombus formation. Haematologica. 2009;94(5):700-71I.

in response to platelet activation, resulting in platelet adhesion and aggregation. Sufficient platelet inhibition is crucial to prevent formation of thrombus and related ischemic events.

Aspirin and thienopyridines have been demonstrated to be of clinical benefit in patients with ACS, and are currently recommended with a Class I level of evidence by the guidelines issued by the American Heart Association, American College of Cardiology, and European Society of Cardiology. ${ }^{4,5}$

\section{Aspirin and thienopyridines in ACS treatment}

By inhibition of cyclo-oxygenase, the enzyme that metabolizes arachidonic acid, a fatty acid from the cell membrane, aspirin irreversibly blocks the formation of thromboxane $\mathrm{A}_{2}$ in platelets, providing an inhibitory effect on platelet aggregation. In the second International Study of Infarct Survival (ISIS-2) in patients with ST segment elevation myocardial infarction (STEMI), the use of aspirin as opposed to placebo was associated with a highly significant reduction in vascular mortality $(9.4 \%$ versus $11.8 \%, P<0.00001)$ along with significant reduction in rates of reinfarction $(1.0 \%$ versus $2.0 \%)$ and nonfatal stroke $(0.3 \%$ versus $0.6 \%)$ at five weeks. ${ }^{6}$

Blockade of the $\mathrm{P} 2 \mathrm{Y}_{12}$ subtype of adenosine diphosphate (ADP) receptor on platelet cell membranes (Figure 1) has been established as another key mechanism of platelet inhibition. Clopidogrel bisulfate (Bristol-Myers Squibb, Princeton, NJ; sanofi-aventis, Bridgewater, NJ), an ADP receptor antagonist and a second-generation thienopyridine, is converted from the inactive parent compound to the active metabolite via the cytochrome $P$ system in a two-step process. The active metabolite of clopidogrel binds to the P2 ${ }_{12}$ ADP receptor site causing irreversible inhibition of platelet aggregation for the life of the platelet. The clinical benefits associated with inhibiting the ADP- $\mathrm{P} 2 \mathrm{Y}_{12}$ receptor pathway of platelet activation with clopidogrel in addition to aspirin were demonstrated in the randomized, placebocontrolled, double-blind Clopidogrel in Unstable Angina to Prevent Recurrent Events (CURE) trial. ${ }^{7}$ Both 12-month primary endpoints (a composite of death from cardiovascular causes, nonfatal myocardial infarction [MI]), or stroke and a composite of death from cardiovascular causes, nonfatal MI, stroke, or refractory ischemia) occurred significantly $(P<0.001)$ less frequently in the clopidogrel group than in the placebo group (9.3\% versus $11.4 \%$ and $16.5 \%$ versus $18.8 \%$, respectively). Among patients undergoing percutaneous coronary intervention (PCI) in the CURE trial, there was a significant $31 \%$ reduction of cardiovascular death or MI at one year (8.8\% versus $12.6 \%, P=0.002$; Figure 2$)$. However, there was a $1 \%$ excess risk of major bleeding in the clopidogrel group compared with the placebo group $(3.7 \%$ versus $2.7 \%, P=0.001$ ).

Prasugrel (Daiichi Sankyo Company, Ltd., Parsippany, NJ; Eli Lilly, Indianapolis, IN), a novel third-generation thienopyridine, like clopidogrel needs cytochrome-dependent 


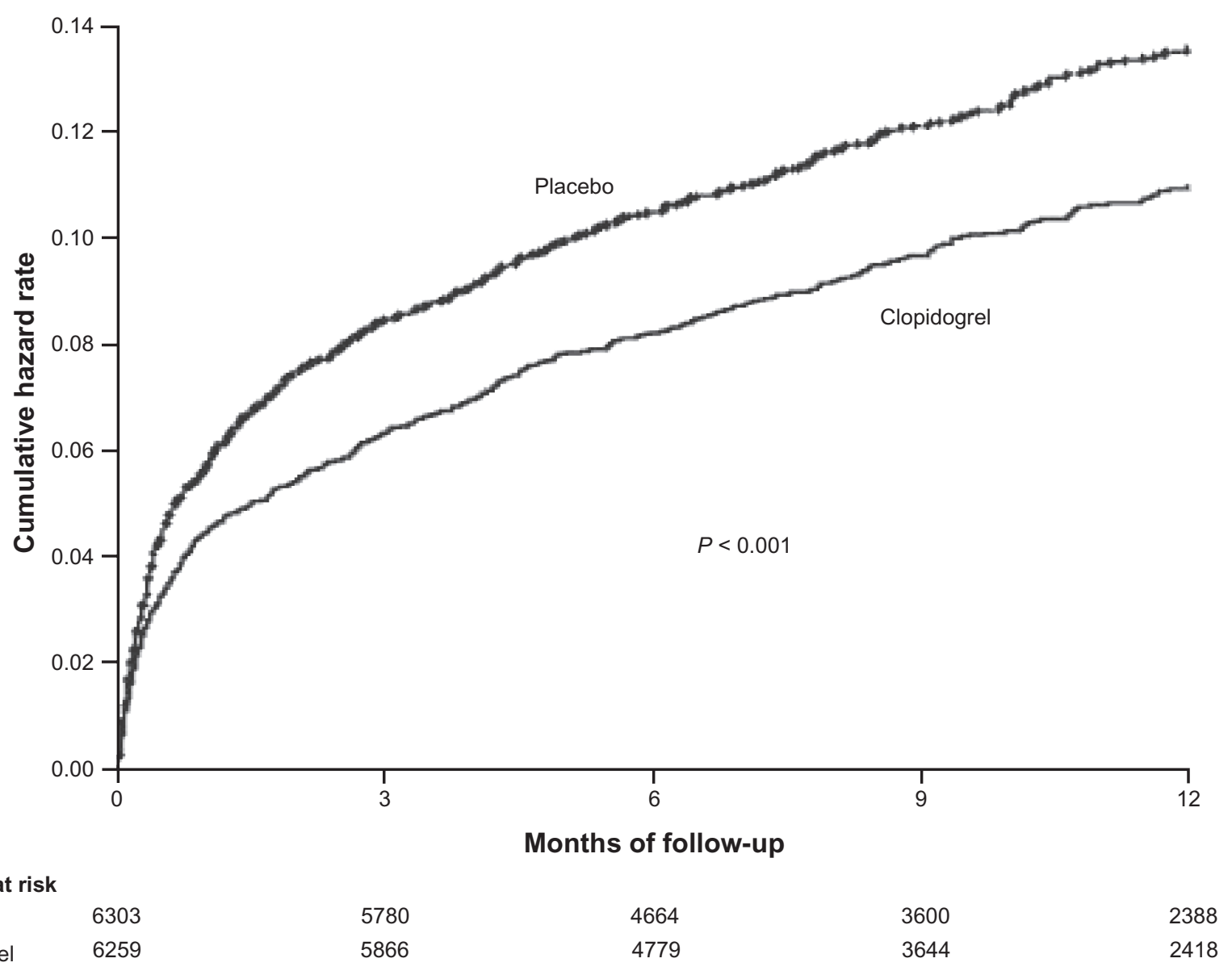

\section{Number at risk}

Placebo

Clopidogrel
6259
4779

3644

Figure 2 Cumulative hazard ratios for the primary endpoint of cardiovascular death, nonfatal myocardial infarction, or stroke during the 12 months of the CURE study. Copyright (C) 200I; Adapted with permission from Yusuf S, Zhao F, Mehta SR, Chrolavicius S, Tognoni G, Fox KK; Clopidogrel in Unstable Angina to Prevent Recurrent Events Trial Investigators. Effects of clopidogrel in addition to aspirin in patients with acute coronary syndromes without ST-segment elevation. N Engl J Med. 200 I;345(7):494-502. Abbreviation: CURE, clopidogrel in unstable angina to prevent recurrent events.

metabolism to gain activity, but requires a single-step for activation, providing stronger inhibition of platelet aggregation than clopidogrel. In the randomized, double-blind, two-phase, crossover Prasugrel in Comparison to Clopidogrel for Inhibition of Platelet Activation and Aggregation-Thrombolysis in Myocardial Infarction 44 (PRINCIPLE-TIMI 44) study, in a total of 201 patients undergoing planned PCI, loading with $60 \mathrm{mg}$ prasugrel as opposed to $600 \mathrm{mg}$ clopidogrel resulted in faster and greater inhibition of platelet aggregation with $20 \mu \mathrm{mol} / \mathrm{L}$ ADP at six hours $(74.8 \% \pm 13.0 \%$ versus $31.8 \% \pm 21.1 \%$, respectively, $P<0.0001) .{ }^{8}$ This difference was evident as early as at 30 minutes $(30.8 \% \pm 29.0 \%$ for prasugrel versus $4.9 \% \pm 13.2 \%$ for clopidogrel, $P<0.001$ ). Similarly, during the maintenance dose phase, inhibition of platelet aggregation after $14 \pm 2$ days of treatment was higher in patients receiving prasugrel $10 \mathrm{mg} /$ day than those receiving clopidogrel $150 \mathrm{mg} /$ day $(61.3 \% \pm 17.8 \%$ versus $46.1 \% \pm 21.3 \%, P<0.0001)$. In the randomized, doubleblind Phase III Trial to Assess Improvement in Therapeutic
Outcomes by Optimizing Platelet Inhibition with PrasugrelThrombolysis in Myocardial Infarction (TRITON-TIMI) 38, involving patients with ACS scheduled for PCI, at a median follow-up of 14.5 months prasugrel therapy was associated with significantly reduced rates of the primary efficacy endpoint of cardiovascular death, nonfatal MI, and nonfatal stroke (9.9\% versus $12.1 \%, P<0.001$, Figure 3$){ }^{9}$

\section{Main limitations of thienopyridines}

Clopidogrel as an antiplatelet agent has several principal drawbacks. The first limitation is related to the metabolism of clopidogrel, which is a prodrug requiring two-step activation involving several hepatic cytochrome $\mathrm{P}$ isoenzymes to convert to the active metabolite. This results in a delayed onset of action (6-8 hours after a $300 \mathrm{mg}$ loading dose) and potentially increases the risk of ischemic events especially in the scenario of urgent coronary intervention. Doubling of the loading dose from $300 \mathrm{mg}$ to $600 \mathrm{mg}$ with a subsequent increase in the maintenance dose from $75 \mathrm{mg}$ to $150 \mathrm{mg}$ for 


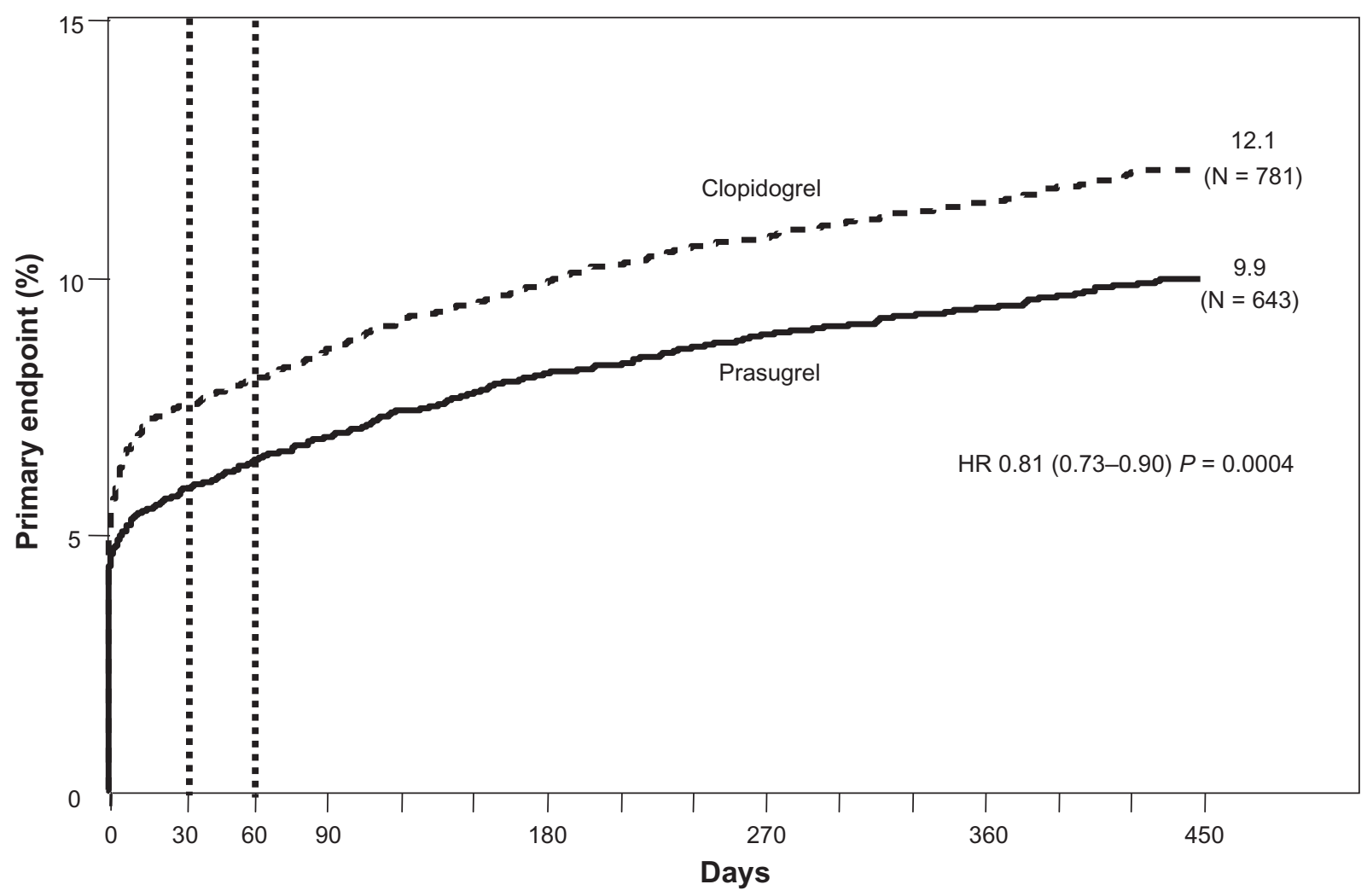

Figure 3 Cumulative HR for the primary endpoint of cardiovascular death, nonfatal myocardial infarction, or nonfatal stroke in the TRITON-TIMI 38 study. Abbreviations: TRITON, trial to assess Improvement in therapeutic outcomes by optimizing platelet inhibition with prasugrel; TIMI, thrombolysis in myocardial infarction; $H R$, hazards ratio.

seven days, in the recently reported randomized Clopidogrel Optimal Loading Dose Usage to Reduce Recurrent Events/ Optimal Antiplatelet Strategy for Interventions (CURRENT OASIS-7) trial in an ACS population (Figure 4) had no significant effect on the primary endpoint of cardiovascular death, MI, or stroke at 30 days $(4.2 \%$ in patients on the high dose versus $4.4 \%$ in patients on the standard dose; hazard ratio [HR] 0.95 , 95\% confidence interval [CI]: 0.84-1.07). ${ }^{10}$ However, among patients managed with PCI within 24 hours (approximately two thirds of the study patients), high-dose clopidogrel yielded a significant $15 \%$ reduction in the composite of cardiovascular, death, MI, or stroke $(3.9 \%$ versus $4.5 \%$, HR $0.85,95 \%$ CI: 0.74-0.99) that was driven mainly by significantly lower rates of MI in the high-dose clopidogrel group (2.0\% versus $2.6 \%$, HR $0.78,95 \%$ CI: $0.64-0.95$ ). There was also a significant $42 \%$ reduction in the risk of the key secondary endpoint of definite stent thrombosis in the high-dose clopidogrel group $(0.7 \%$ versus $1.2 \%$, HR $0.58,95 \%$ CI: $0.42-0.79)$. However, reduction in the rates of ischemic endpoints was offset by higher rates of major bleeding with the higher clopidogrel dose both in the entire study population (2.5\% versus $2.0 \%$; HR 1.25 , 95\% CI: $1.05-1.47)$ and in the PCI population (1.6\% versus 1.1\%; HR 1.44, 95\% CI: 1.11-1.86).
The second limitation of clopidogrel is related to its irreversible binding to $\mathrm{P} 2 \mathrm{Y}_{12}$ receptors, leading to a gradual recovery of platelet function after drug withdrawal. This places patients who need urgent surgical revascularization at increased risk of bleeding within 5-7 days after cessation of clopidogrel. In the CURE study, among patients undergoing coronary artery bypass grafting (CABG), bleeding tended to be more common if CABG was performed within five days of clopidogrel administration (8.5\% with clopidogrel versus $5.7 \%$ with placebo, $P=0.07)$, compared with longer than five days $(4.4 \%$ versus $5.3 \%, P=0.53) .{ }^{11}$ Furthermore, in a prospective study of 224 consecutive patients undergoing nonemergent first-time $\mathrm{CABG}$, patients with versus without preoperative clopidogrel exposure within seven days had greater 24-hour mean chest tube output (1224 mL versus $840 \mathrm{~mL}, P=0.001$ ), were less frequently extubated within eight hours $(54.2 \%$ versus $75.8 \%, P=0.002)$, required more frequent transfusions of packed red blood cells (2.51 units versus 1.74 units, $P=0.04$ ), platelets (0.86 units versus 0.24 units, $P=0.001$ ), and fresh frozen plasma (0.68 units versus 0.24 units, $P=0.02$ ), and had significantly higher rates of reoperation for bleeding $(6.8 \%$ versus $0.6 \%, P=0.018) .{ }^{12}$ 


\begin{tabular}{|c|c|c|c|c|c|c|}
\hline & $\begin{array}{l}\text { Standard } \\
\text { dose }\end{array}$ & $\begin{array}{l}\text { Double } \\
\text { dose }\end{array}$ & Hazard ratio & $\begin{array}{l}95 \% \\
\text { Confidence } \\
\text { interval }\end{array}$ & $\begin{array}{l}P \\
\text { value }\end{array}$ & $\begin{array}{l}\text { Interaction } \\
P \text { value }\end{array}$ \\
\hline \multicolumn{7}{|l|}{ CV Death/MI/Stroke } \\
\hline $\mathrm{PCl}(2 \mathrm{~N}=17,232)$ & 4.5 & 3.9 & 0.85 & $0.74-0.99$ & 0.036 & \multirow{2}{*}{0.016} \\
\hline No PCl $(2 \mathrm{~N}=7855)$ & 4.2 & 4.9 & 1.17 & $0.95-1.44$ & 0.14 & \\
\hline Overall $(2 \mathrm{~N}=25,087)$ & 4.4 & 4.2 & 0.95 & $0.84-1.07$ & 0.370 & \\
\hline \multicolumn{7}{|l|}{ MI } \\
\hline $\mathrm{PCl}(2 \mathrm{~N}=17,232)$ & 2.6 & 2.0 & 0.78 & $0.64-0.95$ & 0.012 & \multirow{2}{*}{0.025} \\
\hline No PCl $(2 \mathrm{~N}=7855)$ & 1.4 & 1.7 & 1.25 & $0.87-1.79$ & 0.23 & \\
\hline Overall $(2 \mathrm{~N}=25,087)$ & 2.2 & 1.9 & 0.86 & $0.73-1.03$ & 0.097 & \\
\hline \multicolumn{7}{|l|}{ CV Death } \\
\hline $\mathrm{PCl}(2 \mathrm{~N}=17,232)$ & 1.9 & 1.9 & 0.96 & $0.77-1.19$ & 0.68 & \multirow{2}{*}{1.0} \\
\hline No PCl $(2 \mathrm{~N}=7855)$ & 2.8 & 2.7 & 0.96 & $0.74-1.26$ & 0.77 & \\
\hline Overall $(2 \mathrm{~N}=25,087)$ & 2.2 & 2.1 & 0.96 & $0.81-1.14$ & 0.628 & \\
\hline \multicolumn{7}{|l|}{ Stroke } \\
\hline $\mathrm{PCl}(2 \mathrm{~N}=17,232)$ & 0.4 & 0.4 & 0.88 & $0.55-1.41$ & 0.59 & \multirow{2}{*}{0.50} \\
\hline No PCl $(2 \mathrm{~N}=7855)$ & 0.8 & 0.9 & 1.11 & $0.68-1.82$ & 0.67 & \\
\hline Overall $(2 \mathrm{~N}=25,087)$ & 0.5 & 0.5 & 0.99 & $0.70-1.39$ & 0.950 & \\
\hline
\end{tabular}

Figure 4 Rates of 30-day primary and secondary endpoints in the CURRENT OASIS-7 trial.

Abbreviation: CURRENT OASIS-7, clopidogrel optimal loading dose usage to reduce recurrent events/optimal antiplatelet strategy for interventions.

The broad interindividual variability in levels of platelet inhibition achieved with clopidogrel is the third limitation of clopidogrel as an antiplatelet agent. Clopidogrel results in only $30 \%$ to $40 \%$ mean inhibition of platelet aggregation response to ADP, with up to one third of patients having inadequate platelet inactivation ("nonresponders"). ${ }^{13}$ This has particular significance given that clopidogrel resistance correlates with higher rates of ischemic events. ${ }^{14}$

Within the last few years, bleeding is gaining recognition as the most common complication in patients with ACS. ${ }^{15}$ Because hemorrhagic events confer an unfavorable prognosis in patients with ACS, ${ }^{16-18}$ bleeding and ways of preventing it assume particular importance. Increased risk of hemorrhagic events is the main disadvantage of prasugrel as compared with clopidogrel. In the randomized, double-blind TRITON-TIMI 38 trial, treatment with prasugrel was associated with an increased rate of non-CABG-related major TIMI bleeding $(2.4 \%$ versus $1.8 \%, P=0.03)$, including life-threatening bleeding $(1.4 \%$ versus $0.9 \%, P=0.01)$ and fatal bleeding $(0.45 \%$ versus $0.15 \%$, $P=0.002) .{ }^{9}$ Besides, CABG-related major TIMI bleeding occurred more frequently with prasugrel $(13.4 \%$ versus $3.2 \%$, $P<0.001$ ), including two cases of fatal bleeding in the prasugrel group versus none in the clopidogrel group. These data prompted the Food and Drug Administration Cardiovascular and Renal Drugs Advisory Committee to recommend avoiding using prasugrel close to surgical procedures. The relative risk of bleeding with prasugrel was higher in patients weighing less than $65 \mathrm{~kg}$ (HR 1.73, 95\% CI: 1.07-2.79, $P<0.05$ ) and patients 75 years of age or older (HR 1.35, 95\% CI: $0.97-1.88$, $P=0.078)$. The rates of hemorrhagic stroke were also remarkably higher in patients with a history of prior stroke or transient ischemic attack treated with prasugrel than with clopidogrel (6.5\% versus $1.2 \%, P=0.002){ }^{9}$

Given the abovementioned limitations of the secondand third-generation thienopyridines, there is an obvious clinical need to improve on the benefits observed with clopidogrel and prasugrel. The ever continuing development of pharmacotherapy for ACS is directed towards creating an antiplatelet agent that will overcome the limitations of the currently available thienopyridines, have a better safety profile, and have at least equivalent efficacy compared with the thienopyridines.

\section{Ticagrelor}

Chemical structure, pharmacodynamics, and pharmacokinetics

Ticagrelor (formerly AZD6140; AstraZeneca, Wilmington, DE) is the first oral agent in a new chemical class of 
nonthienopyridine antiplatelet agents termed cyclopentyltriazolo-pyrimidines (Figure 5). Like the thienopyridines, ticagrelor blocks the platelet $\mathrm{P} 2 \mathrm{Y}_{12}$ receptor to inhibit the prothrombotic effects of ADP. ${ }^{19}$ Ticagrelor binds reversibly to $\mathrm{P} 2 \mathrm{Y}_{12}$ without requiring metabolic activation. ARC124910XX is an active metabolite of ticagrelor, but the parent compound was shown to account for the majority of the antiplatelet effect. ${ }^{19,20}$ It needs only $1.5-3.0$ hours to reach peak plasma levels, allowing a rapid antiplatelet effect. Ticagrelor's half-life is approximately 12 hours and its antiplatelet effect is low at 48 hours after the last dose. ${ }^{19}$ In healthy volunteers, AZD6140 given as single oral doses of $100 \mathrm{mg}$ to $400 \mathrm{mg}$ had linear pharmacokinetics, nearly completely inhibited platelet aggregation two hours postdose, with a reduction of inhibition over the 24-hour postdose period, and was well tolerated. ${ }^{21}$

\section{Clinical studies of ticagrelor}

A randomized, double-blind, parallel-group study by Husted et al assessed the pharmacodynamics, pharmacokinetics, safety, and tolerability of ticagrelor with aspirin relative to that of clopidogrel in combination with aspirin in 200 patients with stable atherosclerotic disease. ${ }^{20}$ The principal aim of the study was to compare the safety of four different doses of AZD6140 (50 mg, $100 \mathrm{mg}$, or $200 \mathrm{mg}$ twice a day, and $400 \mathrm{mg}$ once a day) with that of clopidogrel (75 mg once a day) in combination with aspirin (75 to $100 \mathrm{mg}$ once a day) in order to choose the optimal dose to be further investigated in clinical trials. No loading dosages of the drugs were administered in this study. According to the results, AZD6140 at the doses of $100 \mathrm{mg}$ twice a day, $200 \mathrm{mg}$ twice a day, and $400 \mathrm{mg}$ once a day were superior to AZD6140 at a dose of $50 \mathrm{mg}$ twice a day and clopidogrel $75 \mathrm{mg}$ once a day with regard to $\mathrm{P} 2 \mathrm{Y}_{12}$-mediated platelet aggregation as measured by optical aggregometry both after initial dosing and at steady state. On day 1 , the onset of peak inhibition of platelet aggregation occurred by two hours after AZD6140 administration, while inhibition of platelet aggregation was

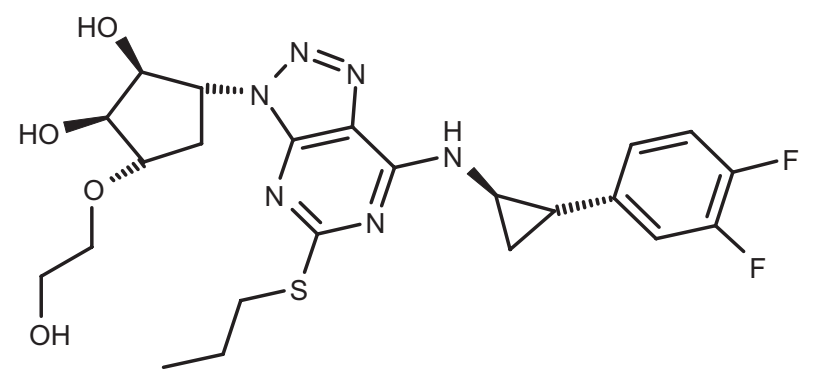

Figure 5 Structural formula for bivalirudin.

Notes: Ticagrelor (AZD6|40), a cyclo-pentyl-triazolo-pyrimidine, an oral reversible P2YI2 antagonist. minimal with clopidogrel. Remarkably, inhibition of platelet aggregation with AZD6140 was reversible, as shown by the declining levels of inhibition of platelet aggregation at 24 hours after the last dose. With regard to safety, AZD6140 at the three higher doses was associated with more bleeding episodes than clopidogrel, although all but one bleeding event were qualified as minor. The sole major bleeding event was observed with AZD6140 400 mg once a day. Moreover, AZD6140 $100 \mathrm{mg}$ twice a day and $200 \mathrm{mg}$ twice a day appeared to have a more favorable safety and tolerability profile than AZD6140 $400 \mathrm{mg}$ once a day with regard to frequency of dyspnea and ventricular pauses on Holter monitoring. Therefore, these two doses were selected for subsequent clinical evaluation.

The randomized, double-blind, double-dummy DISPERSE (Dose confIrmation Study assessing anti-Platelet Effects of AZD6140 versus clopidogRel in non-ST segment Elevation myocardial infarction)-2 trial further evaluated the safety, tolerability, and initial efficacy of either AZD6140 or clopidogrel added to aspirin in 990 patients with non-ST-segment elevation ACS. ${ }^{22}$ The patients were randomized in a 1:1:1 fashion to receive AZD6140 $90 \mathrm{mg}$ twice a day, AZD6140 $180 \mathrm{mg}$ twice a day, or a clopidogrel $300 \mathrm{mg}$ loading dose plus $75 \mathrm{mg}$ a day for up to 12 weeks. Patients in the AZD6140 group were further randomized to receive or not receive the $270 \mathrm{mg}$ loading dose of the drug. The primary endpoint, ie, Kaplan-Meier rate of protocol-defined major or minor bleeding over four weeks, did not differ between the three groups $(9.8 \%, 8.0 \%$, and $8.1 \%$, respectively). Rates of major bleeding were also close $(7.1 \%, 5.1 \%$, and $6.9 \%$, respectively). Notably, the bleeding rates were not different regardless of previous treatment with clopidogrel, or administration of a loading dose of AZD6140 or platelet glycoprotein IIb/IIIa inhibitors. Asymptomatic ventricular pauses longer than $2.5 \mathrm{sec}$ were more common with AZD6140, particularly at $180 \mathrm{mg}$ twice a day $(5.5 \%, 9.9 \%$, and $4.3 \%$, respectively; $P=0.58$ and $P=0.01$, respectively, versus clopidogrel). Remarkably also, the study highlighted for the first time that among patients undergoing CABG 1-5 days after stopping the drug, treatment with AZD6140 as opposed to clopidogrel was associated with a numerically lower incidence of major bleeding, a finding consistent with the reversible inhibition of the $\mathrm{P} 2 \mathrm{Y}_{12}$ receptor provided with AZD6140.

The ONSET/OFFSET study was a multicenter, randomized, double-blind, double-dummy, parallel-group study aimed at a comprehensive comparison of AZD6140 versus high-loading-dose clopidogrel antiplatelet onset and offset effect profile in 123 patients with stable coronary artery 
disease. ${ }^{23}$ In this study, the patients treated with aspirin (75-100 mg a day) randomly received AZD6140 (a $180 \mathrm{mg}$ loading dose and maintenance dose of $90 \mathrm{mg}$ twice a day), clopidogrel (600 mg loading dose, $75 \mathrm{mg}$ once a day maintenance dose), or placebo for six weeks. Inhibition of platelet aggregation was significantly (all $P<0.0001$ ) more prominent with AZD6140 than with high-loading dose clopidogrel at any study point $(0.5$, one, two, four, eight, and 24 hours after loading dose and at six weeks). The study also showed very rapid onset and fast offset of the antiplatelet effect of AZD6140 (Figure 6). Namely, at one hour after the loading dose, platelet inhibition provided by AZD6140 was approximately 1.6 times greater than the maximal platelet inhibition induced by clopidogrel that occurred only at eight hours after loading. Inhibition of platelet activity at 24 hours after the last dose was equivalent in AZD6140- and clopidogreltreated patients, while inhibition of platelet aggregation at 48 hours after the last dose was numerically less at 48 hours and significantly less at 72 and 120 hours with AZD6140. Combined together, these data confirmed faster immediate offset of effect for AZD6140 relative to clopidogrel and further strengthened the observation from the DISPERSE-2 trial that bleeding risk may be lower in patients undergoing surgery 48-120 hours after AZD6140 discontinuation. ${ }^{22}$

The RESPOND (Response to Ticagrelor in Clopidogrel Nonresponders and Responders and Effect of Switching Therapies) study was a randomized, double-blind, doubledummy crossover trial that examined the use of ticagrelor in 98 patients with stable coronary artery disease as a function of responsiveness to clopidogrel. ${ }^{24}$ Nonresponsiveness to clopidogrel was defined as a $\leq 10 \%$ absolute change in $20 \mu \mathrm{mol} / \mathrm{L}$ ADP-induced platelet aggregation between the baseline value and at $6-8$ hours after the $300 \mathrm{mg}$ clopidogrel loading dose. In a two-way crossover design, nonresponders and responders were randomly assigned to receive clopidogrel (600 mg loading dose then $75 \mathrm{mg}$ once daily) or

\section{$20 \mu M$ ADP- Final Extent}

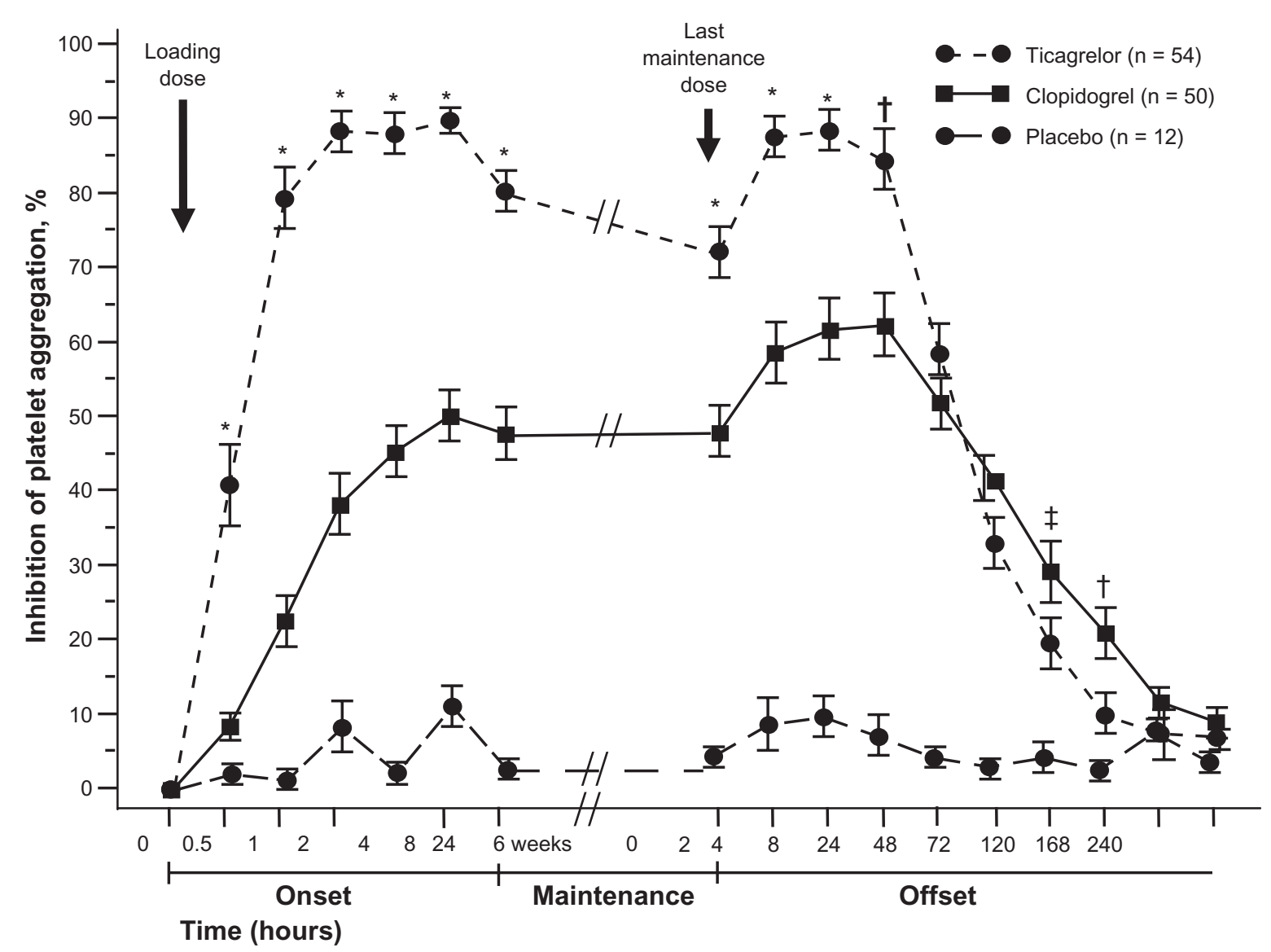

Figure 6 Inhibition of platelet aggregation by protocol time and treatment in the ONSET/OFFSET study. Copyright @ 2003. Adapted with permission Gurbel PA, Bliden KP, Hiatt BL, O'Connor CM. Clopidogrel for coronary stenting: Response variability, drug resistance, and the effect of pretreatment platelet reactivity. Circulation. 2003; I07(23):2908-29I3. Notes: $* P<0.0001,+P<0.005, \ddagger P<0.05$, ticagrelor versus clopidogrel.

Abbreviation: ONSET/OFFSET, a randomized double-blind study to assess the onset and offset of the antiplatelet effects of ticagrelor versus clopidogrel in patients with stable coronary artery disease. 
ticagrelor (180 mg loading dose then $90 \mathrm{mg}$ twice daily) for 14 days (period 1). Thereafter, all nonresponders switched treatment, with half of the responders continuing the previous treatment, and half switching treatment. The use of ticagrelor among nonresponders resulted in a $>10 \%,>30 \%$, and $>50 \%$ decrease in platelet aggregation from baseline in $100 \%, 75 \%$, and $13 \%$ of patients, respectively. In addition, there was a significant $(P<0.0001)$ decrease in platelet aggregation from a mean $59 \%$ to $35 \%$ in patients switched from clopidogrel to ticagrelor and an increase in platelet aggregation from mean $36 \%$ to $56 \%$ in patients switched from ticagrelor to clopidogrel. These results indicated that the antiplatelet effect of ticagrelor is consistent regardless of responsiveness to clopidogrel, that ticagrelor may represent a logical substitute for clopidogrel nonresponders, and that platelet inhibition in patients responsive to clopidogrel may be significantly augmented by switching to ticagrelor without reduction in antiplatelet effect.

\section{Platelet Inhibition and Patient Outcomes trial}

PLATO (Platelet Inhibition and Patient Outcomes) was a multicenter, double-blind, double-dummy, randomized Phase III trial conducted at 862 centers in 43 countries comparing ticagrelor (180 mg loading dose then $90 \mathrm{mg}$ twice a day thereafter) and clopidogrel (300 to $600 \mathrm{mg}$ loading dose then $75 \mathrm{mg}$ a day thereafter) for the prevention of cardiovascular events in 18,624 patients with ACS (Figure 7). ${ }^{25,26}$ The primary efficacy endpoint was time to the first occurrence of death from vascular causes, MI, or stroke. The principal secondary efficacy endpoint was the primary efficacy endpoint examined in the subgroup of patients triaged to invasive management.

Ticagrelor demonstrated superiority to clopidogrel in reducing rates of the primary endpoint of death from cardiovascular causes, MI, or stroke at 12 months $(9.8 \%$ versus $11.7 \%, P<0.001$, Figure 8$)$. A significant difference in rates of the primary endpoint was observed at 30-day follow-up which persisted at one year (Figures 9A and 9B). Remarkably, there was also a significant reduction in the rate of individual endpoints with ticagrelor, including allcause death $(4.5 \%$ versus $5.9 \%, P<0.001)$, cardiovascular death $(4.0 \%$ versus $5.1 \%, P=0.001)$, and MI (5.8\% versus $6.9 \%, P=0.005)$. By subgroup analysis, the results in favor of ticagrelor were consistent in the 33 subgroups, with the exception of patients weighing less than the median weight for their gender, patients not taking lipid-lowering drugs at randomization, and patients enrolled in North America. ${ }^{26}$ Patients in North America had nonsignificantly higher rates for the primary endpoint when treated with ticagre-

\section{PLATO study design}
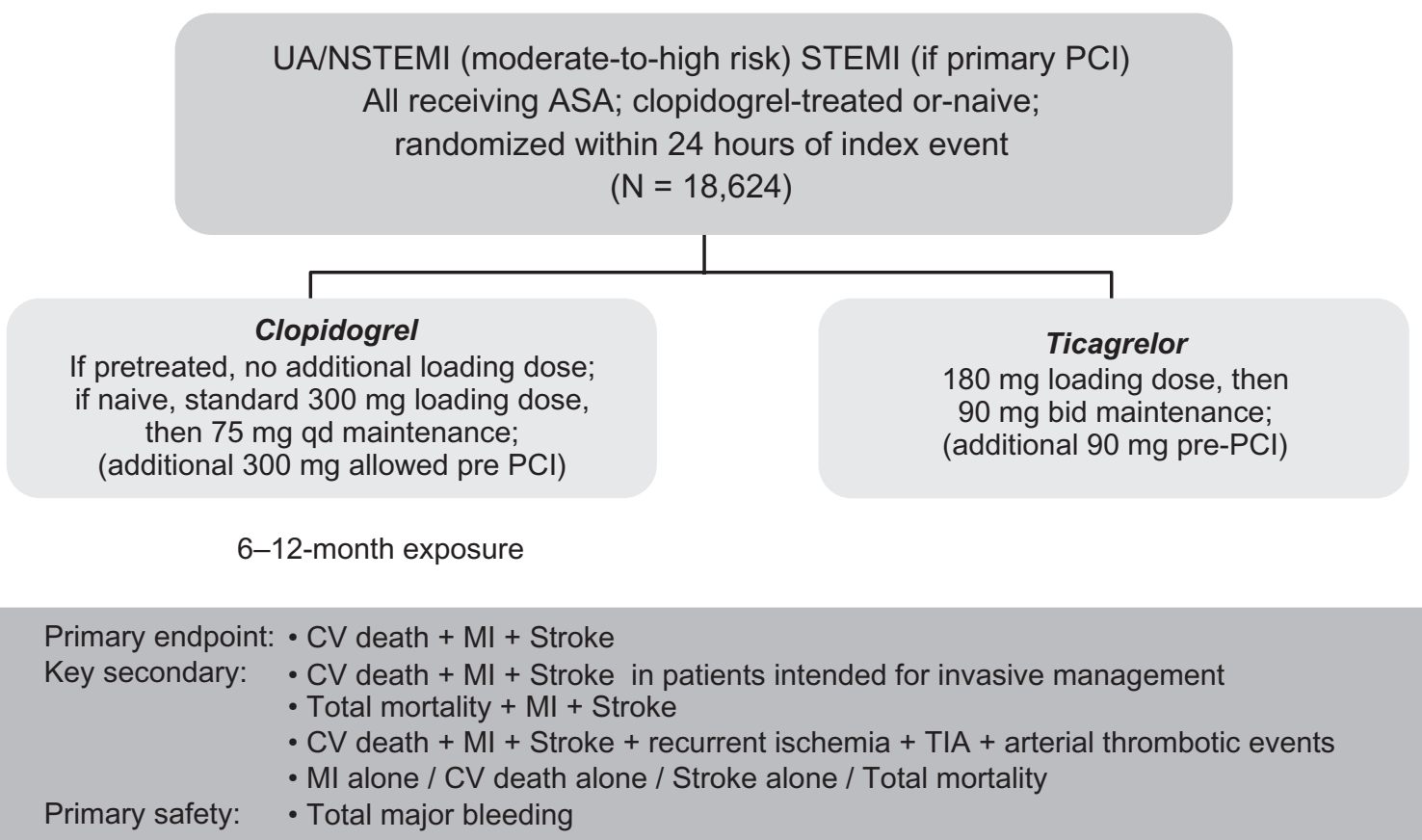

Figure 7 The Platelet Inhibition and Patient Outcomes study algorithm.

Abbreviation: PLATO, platelet inhibition and patient outcomes.

Abbreviations: UA, unstable angina; $\mathrm{PCl}$, percutaneous coronary intervention; ASA, acetylsalicylic acid; CV, cardiovascular; TIA, transient ischemic attack. 


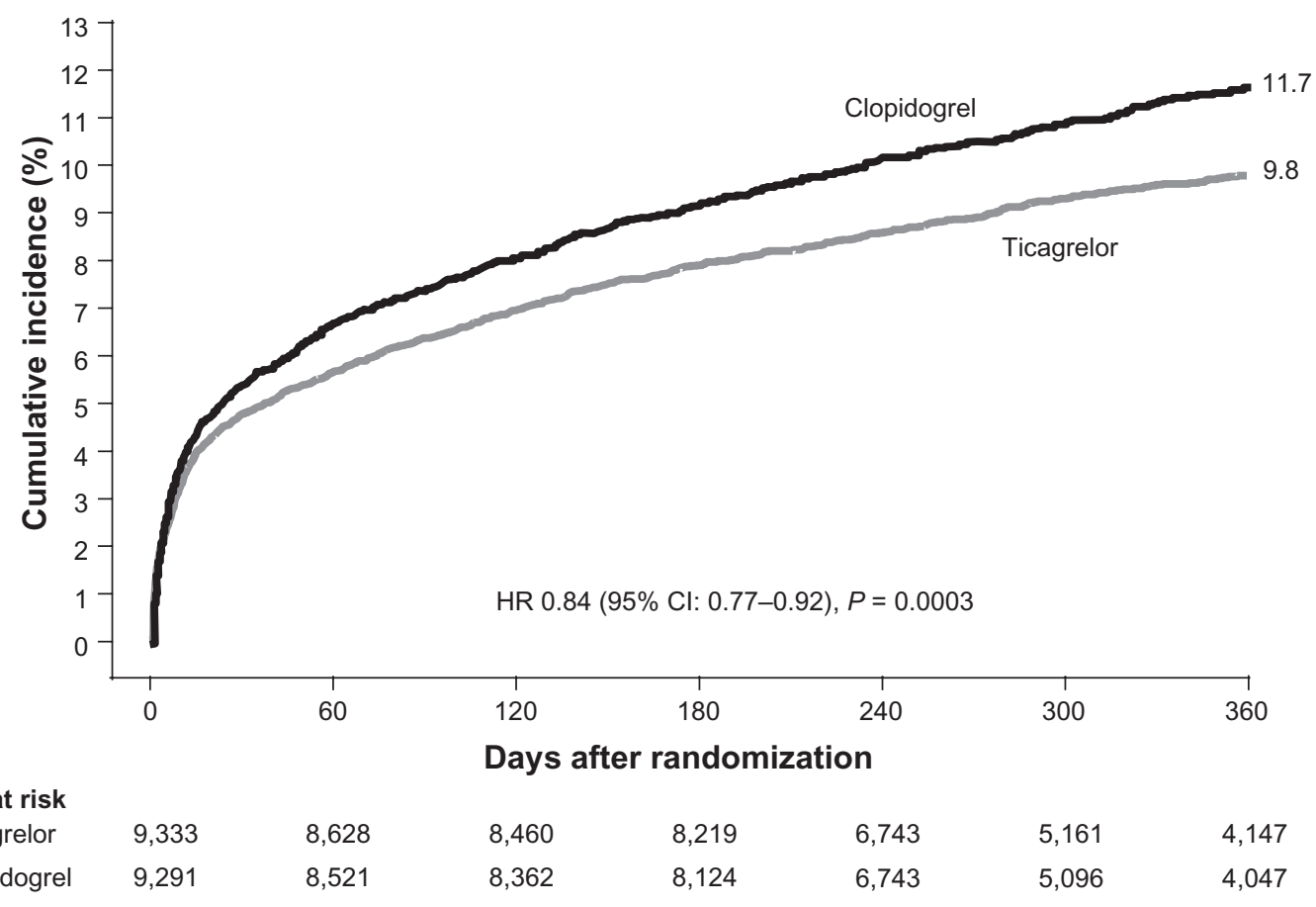

Figure 8 Kaplan-Meier estimate of time to first primary efficacy event (composite of cardiovascular death, myocardial infarction, or stroke) in PLATO trial. Abbreviation: PLATO, platelet inhibition and patient outcomes.

lor than those treated with clopidogrel (HR 1.25, 95\% CI: 0.93-1.67). The reasons for the diverse outcomes in different geographic regions are not known, and might be related but not limited to the differences in demographics, patient compliance, and standards of ACS care. Higher dosages of aspirin were used in the North American population than in the rest of the study population. Further research is needed to clarify whether there are region-specific differences in

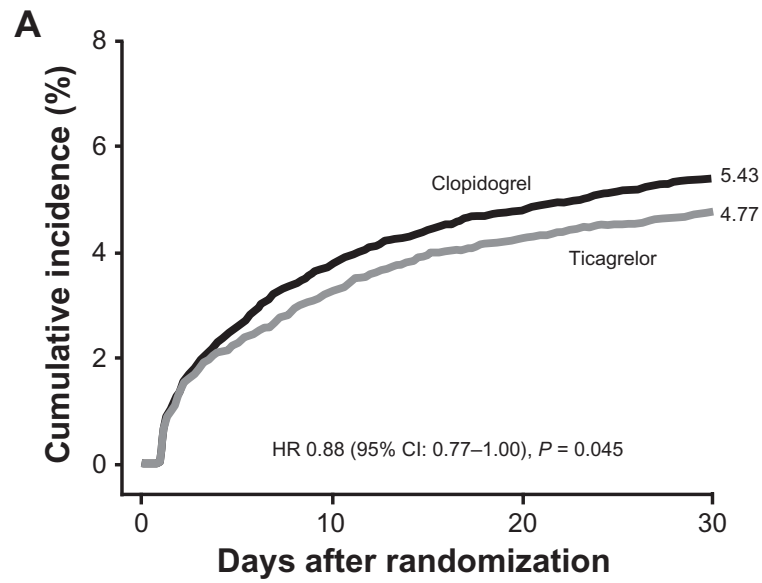

$\begin{array}{lllll}\text { Ticagrelor } & 9,333 & 8,942 & 8,827 & 8,763 \\ \text { Clopidogrel } & 9,291 & 8,875 & 8,763 & 8,688\end{array}$

No. at risk

outcomes for ACS patients treated with ticagrelor versus aspirin.

The incidence of protocol-defined major bleeding was almost identical between ticagrelor and clopidogrel (11.6\% versus $11.2 \%$, respectively, $P=0.43$, Figures 10 and 11 ). The same was true with regard to the incidence of major TIMI (Thrombolysis in Myocardial Infarction) bleeding, or fatal or life threatening bleeding (Figure 11). In subgroup

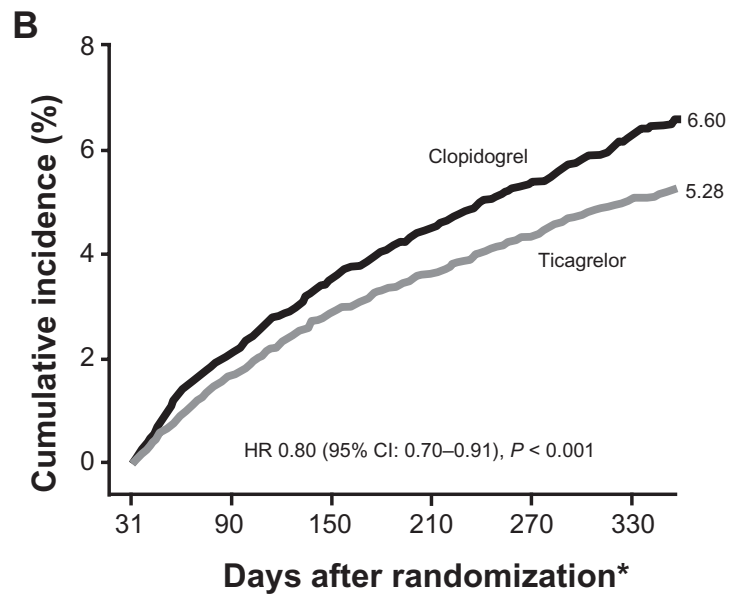

igure 9 Landmark analysis of composite endpoint of cardiovascular death, myocardial infarction, or stroke during the first 30 days after randomization $\mathbf{A}$ and at later follow-up B.

Notes: *Excludes patients with any primary event during the first 30 days. 


\section{Type of bleeding}

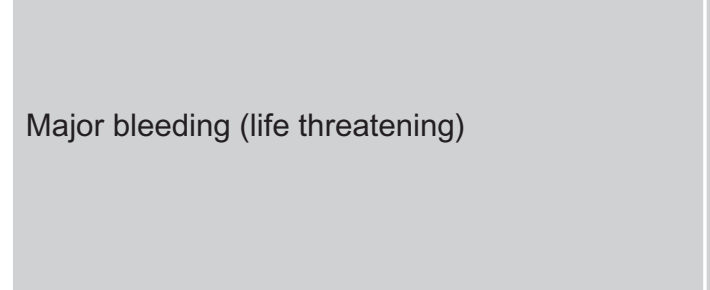

Major bleeding - other

Minor bleeding

Minimal bleeding

\section{Definition}

Fatal or intracranial or intrapericardial with cardiac tamponade or hypovolemic shock or severe hypotension requiring vasopressors or surgery or bleeding with associated drop in hemoglobin of $>50 \mathrm{~g} / \mathrm{L}(3.1 \mathrm{mmol} / \mathrm{L})$ or blood/packed red blood cells transfusion $\geq 4$ units.

Significantly disabling (eg, intraocular with permanent vision loss); Associated drop in hemoglobin of 30-50 g/L (1.9-3.1 mmol/L); Transfusion of 2-3 units

Requires medical intervention to stop or treat bleeding

All others not requiring intervention or treatment

Figure 10 Definitions of bleeding in the PLATO trial.

Abbreviation: PLATO, platelet inhibition and patient outcomes.

analysis, the absence of a significant difference in rate of major bleeding was consistent among all the studied subgroups, apart from body mass index ( $P=0.05$ for interaction). Rates of CABG-related major bleeding or bleeding requiring transfusion were also similar between the two groups. However, in the ticagrelor group, there was a higher rate of
non-CABG-related major bleeding according to the study criteria $(4.5 \%$ versus $3.8 \%, P=0.03)$ and TIMI criteria ( $2.8 \%$ versus $2.2 \%, P=0.03)$. With ticagrelor as compared with clopidogrel, there were more episodes of intracranial bleeding (26 [0.3\%] versus $14[0.2 \%], P=0.06)$, including fatal intracranial bleeding (11 [0.1\%] versus one [0.01\%],

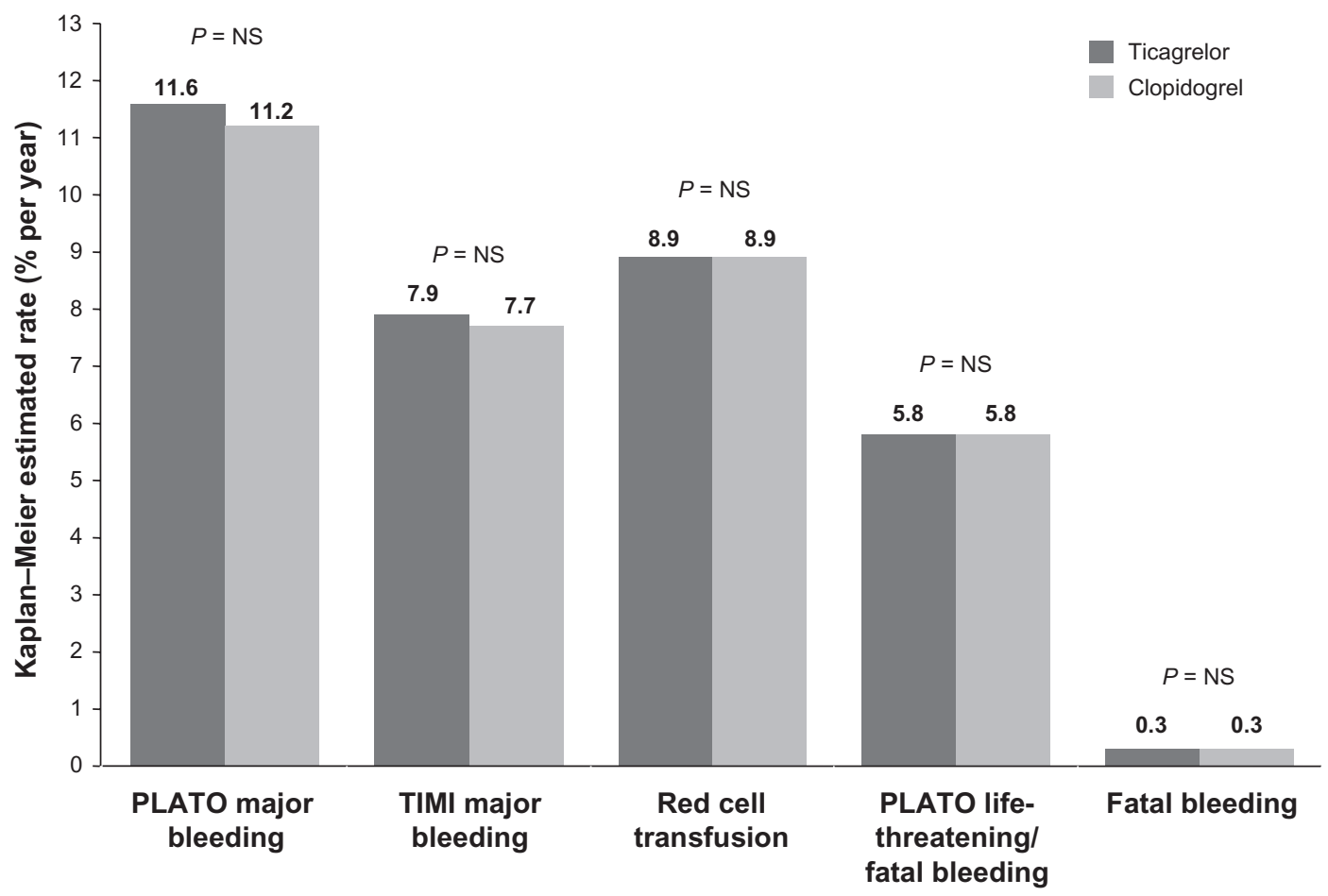

Figure II Rates of all major bleeding (related and not related to coronary artery bypass grafting) by PLATO scale, major bleeding by TIMI scale, red cell transfusion, life threatening/fatal bleeding by PLATO scale and fatal bleeding in the PLATO trial. All $P$ values are nonsignificant (NS).

Abbreviations: PLATO, platelet inhibition and patient outcomes; TIMI, thrombolysis in myocardial infarction. 
$P=0.02)$ but fewer episodes of other types of fatal bleeding (9 [0.1\%], versus $21[0.3 \%] ; P=0.03) .{ }^{26}$

The following adverse effects were more commonly associated with ticagrelor in the PLATO trial. Patients treated with ticagrelor experienced dyspnea significantly more often than those treated with clopidogrel $(13.8 \%$ versus $7.8 \%$, respectively, $P<0.001$ ), albeit this rarely resulted in study drug discontinuation $(0.9 \%$ in the ticagrelor group versus $0.1 \%$ in the clopidogrel group).

There was also a higher incidence of ventricular pauses $\geq$ three seconds in duration by Holter monitoring during the first week of treatment in the ticagrelor group $(5.8 \%$ versus $3.6 \%$, $P=0.01)$ but this did not translate into a higher incidence of syncope $(1.1 \%$ versus $0.8 \%, P=0.08)$ or pacemaker insertion $(0.9 \%$ in both groups, $P=0.87)$. Although the exact reasons for more frequent episodes of dyspnea and ventricular pauses with ticagrelor are not known, the most plausible mechanism is related to the structural similarity of ticagrelor to adenosine and possibly altered reuptake of adenosine by red blood cells. Finally, patients treated with ticagrelor as opposed to clopidogrel had a more pronounced increase in serum creatinine and uric acid at one month and at one year, although the differences did not exist after one month of drug discontinuation. ${ }^{26}$

\section{Ticagrelor in patients with a planned invasive strategy}

A total of 13,408 patients, comprising $72 \%$ of the entire PLATO population with ACS, were planned by the site investigators at the time of randomization to be managed with an invasive approach, including early coronary angiography with subsequent revascularization (PCI or CABG), when appropriate. ${ }^{27}$ Approximately half of the patients had had a STEMI. A total of 11080 patients were triaged to revascularization, including 10,298 patients who were triaged to $\mathrm{PCI}$ and 782 patients who were triaged to CABG. Median time to PCI was 2.4 hours (interquartile range $0.8-20$ ) post randomization in patients with non-STEMI or unstable angina, and 0.5 hours (interquartile range $0.2-1.0$ ) in patients with STEMI, and median time to CABG was six days (interquartile range 3-10).

The results in patients managed with an invasive strategy in fact repeated the results in the entire PLATO population. Ticagrelor was superior to clopidogrel in terms of reduction of the primary composite endpoint (cardiovascular death, MI, or stroke, Figure 12) and secondary endpoints of cardiovascular mortality and MI (Figures 13A and 13B). All-cause mortality rate was also significantly reduced with ticagrelor $(3.9 \%$ versus $5.0 \%, P=0.03)$. The benefit of ticagrelor versus clopidogrel for the primary endpoint was similar across a wide range of subgroups, irrespective of the loading dose of clopidogrel and the use of platelet glycoprotein IIb/IIIa inhibitors.

Among patients triaged to PCI, ticagrelor was associated with significantly reduced rates of definite stent thrombosis (1.3\% versus $2.0 \%, P=0.005)$, including patients treated with drug-eluting stents $(1.3 \%$ versus $1.8 \%, P=0.23)$ and bare-metal stents $(1.4 \%$ versus $2.1 \%, P=0.012)$. Rates of definite stent thrombosis were lower with ticagrelor, regardless of whether the patients received a clopidogrel loading dose of $600 \mathrm{mg}$ or less.

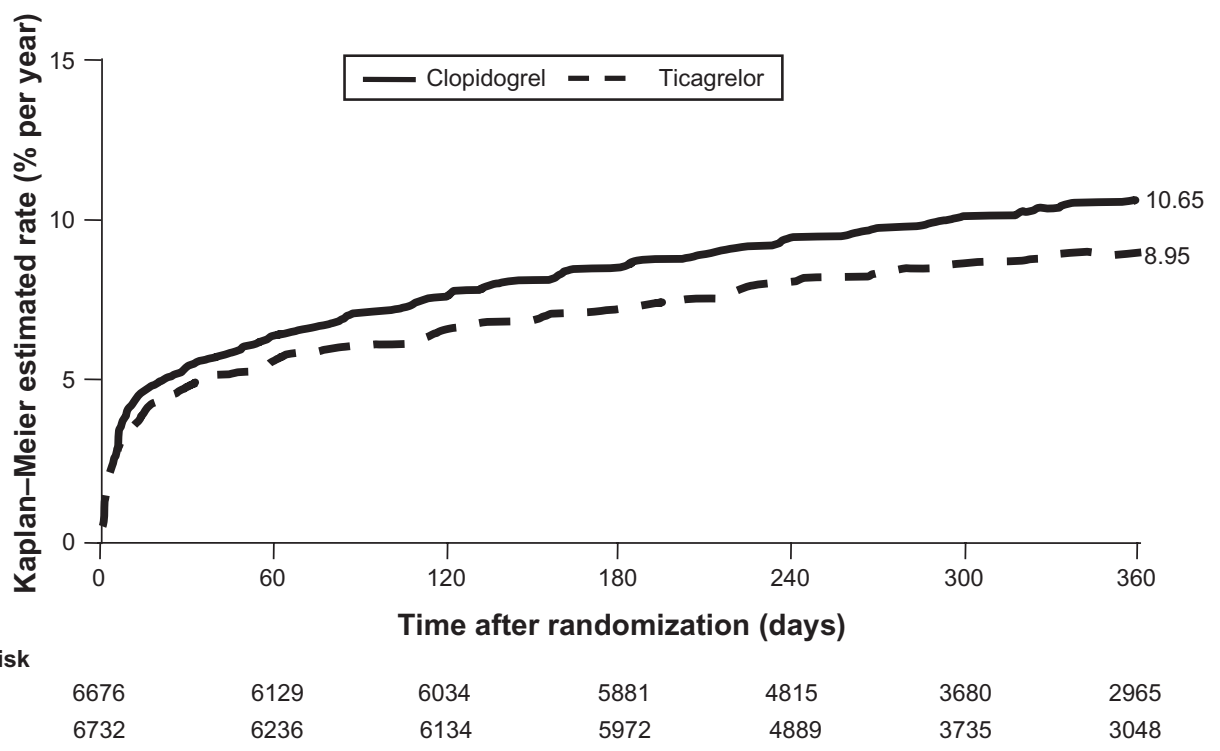

Figure 12 Cumulative Kaplan-Meier estimates of time to first primary efficacy endpoint (cardiovascular death, myocardial infarction, or stroke) in patients triaged to an invasive strategy. Copyright (C) 20I0. Adapted with permission from Cannon CP, Harrington RA, James S, et al; PLATelet inhibition and patient Outcomes Investigators. Comparison of ticagrelor with clopidogrel in patients with a planned invasive strategy for acute coronary syndromes (PLATO): a randomised double-blind study. Lancet. 2010;375(97II):283-293. 

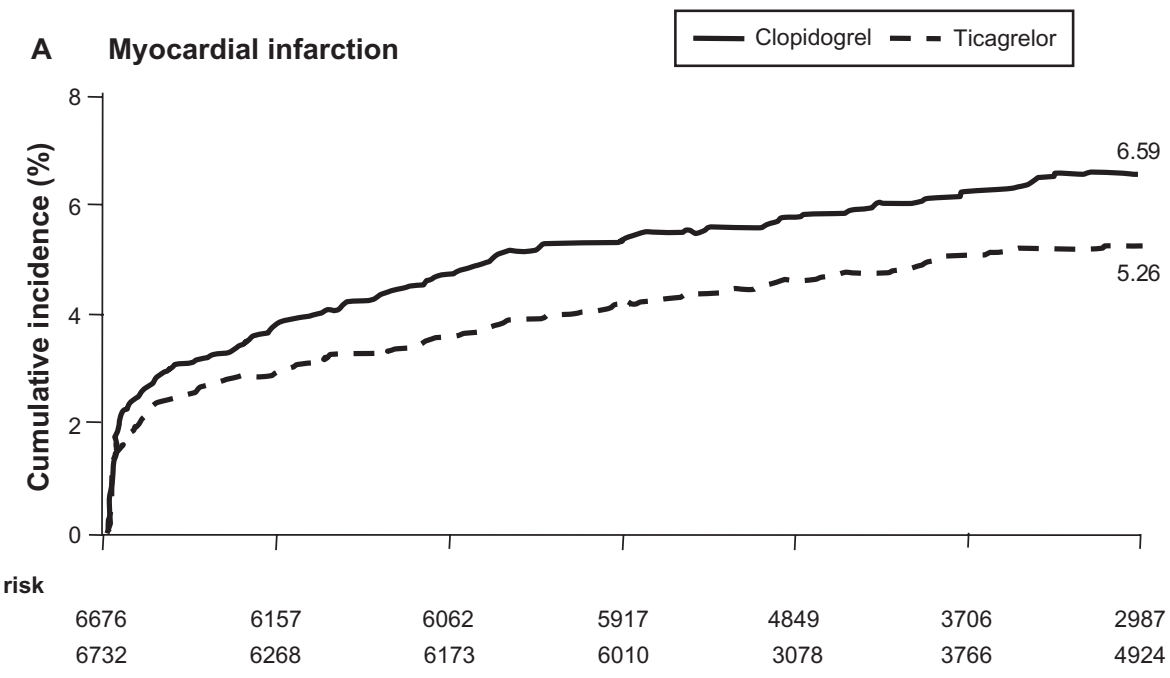

B Cardiovascular death

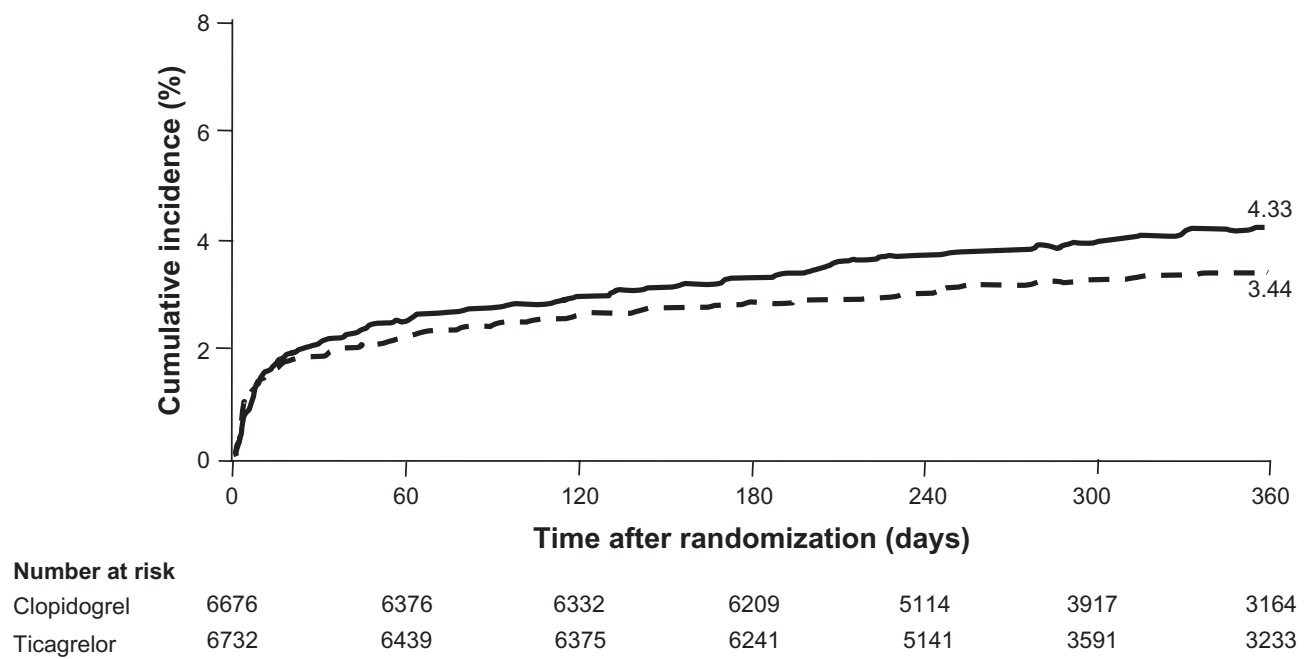

Figure 13 Cumulative Kaplan-Meier estimates of time to myocardial infarction A or cardiovascular death B in patients triaged to an invasive strategy. Copyright $($ ) 20I0. Adapted with permission from Cannon CP, Harrington RA, James S, et al; PLATelet inhibition and patient Outcomes Investigators. Comparison of ticagrelor with clopidogrel in patients with a planned invasive strategy for acute coronary syndromes (PLATO): a randomised double-blind study. Lancet. 20 I0;375(97I I):283-293.

The rates of PLATO-defined total major bleeding $(11.5 \%$ in the ticagrelor group versus $11.6 \%, P=0.88)$, fatal or lifethreatening bleeding $(6.0 \%$ versus $5.9 \%, P=0.61)$, or other major bleeding $(5.9 \%$ versus $6.2 \%, P=0.40)$, as well as major TIMI bleeding $(7.9 \%$ versus $7.9 \%, P=1.0)$, severe GUSTO bleeding ( $2.9 \%$ versus $3.2 \%, P=0.38)$, or transfusion of whole blood/packed red blood cells $(8.9 \%$ versus $8.7 \%$, $P=0.91)$ or platelets $(1.6 \%$ versus $1.9 \%, P=0.25)$ did not differ between the two groups. The rates of major non-CABG bleeding by PLATO definition were not significantly higher $(4.7 \%$ versus $4.0 \%, P=0.10)$ and those of CABG-related bleeding were not significantly lower $(7.1 \%$ versus $8.0 \%$, $P=0.07)$ with ticagrelor.

In the subgroup analysis from the PLATO trial of 8430 patients with STEMI undergoing primary PCI, treatment with ticagrelor as opposed to clopidogrel resulted in lower rates of cardiovascular death, MI, or stroke $(9.3 \%$ versus $11.0 \%$, $P=0.02) .{ }^{28}$ There was also a significant reduction in all-cause death $(4.9 \%$ versus $6.0 \%, P=0.04)$, MI ( $4.7 \%$ versus $6.1 \%$, $P=0.01)$, and definite stent thrombosis $(1.6 \%$ versus $2.5 \%$, $P=0.01$ ) with ticagrelor compared with clopidogrel, without differences in rates of major bleeding between the two drugs ( $9.0 \%$ versus $9.3 \%, P=0.63$ ).

\section{Dyspnea in patients treated with ticagrelor}

Prespecified prospective analysis from the ONSET/OFFSET trial provided comprehensive assessment of cardiac and pulmonary function at baseline and at six-week follow-up in patients treated with ticagrelor as compared with clopidogrel. ${ }^{29}$ The 
analyzed data included echocardiographic assessment of left ventricular ejection fraction, $\mathrm{N}$-terminal pro-brain natriuretic peptide and pulmonary function parameters, including forced expiratory volume in one second $\left(\mathrm{FEV}_{1}\right)$, forced volume vital capacity (FVC), $\mathrm{FEV}_{1} / \mathrm{FVC}$, mean forced expiratory flow between $25 \%$ and $75 \%$ of the FVC, lung volume, total lung capacity, residual volume, minute ventilation, tidal volume, respiratory rate, single-breath diffusing capacity of lung for carbon monoxide, and oxygen saturation. At six weeks, dyspnea was experienced by significantly $(P<0.0001)$ more patients treated with ticagrelor $(38.6 \%)$ as compared with clopidogrel $(9.3 \%)$ or placebo $(8.3 \%)$. The majority of cases of dyspnea, as assessed by the site investigators, were mild defined as awareness of sign or symptom but easily tolerated, and only three patients experienced moderate dyspnea, defined as discomfort sufficient to cause interference with normal activities. In the majority of patients in the ticagrelor group (17 of 22), dyspnea developed within one week, including eight patients in whom dyspnea occurred within the first 24 hours of treatment. Dyspnea persisted up to the end of six weeks in only three patients with dyspnea in the ticagrelor group. There were no significant changes in any of the cardiac or pulmonary parameters in any of the groups between baseline and six-week follow-up assessments. There was also no significant difference in the percent change from baseline to six-week follow-up for all the cardiac and pulmonary measurements between the treatment groups. ${ }^{29}$

\section{Conclusion and future directions}

In the pivotal clinical trials, ticagrelor, a new potent oral direct-acting $\mathrm{P}_{2} \mathrm{Y}_{12}$ inhibitor, demonstrated substantial benefits against clopidogrel, and thus providing a new solution in the care of patients with ACS. Ticagrelor is well tolerated, and has faster and greater platelet inhibition than clopidogrel, making this new agent especially advantageous in the setting of urgent PCI when immediate platelet inhibition is of particular importance. Reversibility is another essential feature of ticagrelor, allowing usage of this agent in certain clinical scenarios, including surgery, in which recovery of platelet function is necessary sooner than the 5-7 days required for clopidogrel. The antiplatelet impact of ticagrelor is to a great extent not dependent on clopidogrel response status, thus overcoming the issue of clopidogrel unresponsiveness. The prospective, randomized PLATO trial has established the clinical utility of ticagrelor in a wide range of patients with ACS managed with contemporary antithrombotic therapies and invasive strategies when indicated. Ticagrelor was proven to be superior to clopidogrel in reduction of the composite endpoint of cardiovascular death, MI, or stroke, and resulted in enhanced survival without an increase in overall major bleeding.

The mechanisms of how ticagrelor affected survival are not known. First, this may be by chance alone. However, a highly significant difference in mortality rates between the ticagrelor and clopidogrel arms makes this explanation unlikely. Second, survival benefit in favor of ticagrelor may be related to the PLATO trial design, in which patients were randomized early from onset of ischemic symptoms (within 24 hours) relative to TRITON-TIMI 38 trial (within 72 hours); the beneficial effect of ticagrelor versus clopidogrel may be more prominent with earlier initiation of antiplatelet therapy. Third, given that ticagrelor prevents adenosine reuptake by red blood cells, it may potentially improve microcirculatory flow and reduce the size of infarction. In a randomized, double-blind, placebo-controlled multicenter trial of adenosine as an adjunct to reperfusion in the treatment of acute myocardial infarction (AMISTAD-II), a $70 \mu \mathrm{g} / \mathrm{kg} / \mathrm{min}$ adenosine infusion correlated with smaller infarct size and fewer clinical events. And last, but not least, enhanced survival with ticagrelor may be related to reduction in rates of MI without increasing bleeding complications, providing further support for the bleeding-ischemia hypothesis raised in previous ACS trials, in which reduction in mortality was parallel to the decrease in major bleeding. ${ }^{30,31}$

The development and clinical introduction of ticagrelor is believed to be changing the standard of care for ACS. ${ }^{32}$ However, further investigation is needed to optimize the antiplatelet strategy to meet the needs of the individual patient with ACS. The twice-daily dosing is a drawback of ticagrelor that may potentially adversely affect patient compliance, and requires further careful studies. Patients with multiple risk factors for bleeding events may not benefit from ticagrelor similarly to prasugrel. A higher incidence of hemorrhagic stroke and gastrointestinal bleeding with ticagrelor compared with clopidogrel is certainly a concern, even if the numbers of events were low in the PLATO trial. There are no data on whether ticagrelor may be used in patients undergoing elective PCI or in combination with fibrinolytic agents. At this time it is also not clear if ticagrelor may be used safely in patients with chronic obstructive pulmonary disease, conduction system abnormalities, hyperuricemia, or chronic kidney disease, all of which warrant further indepth analysis. More studies are also necessary to clarify whether there are true geographic differences in outcomes between patients treated with ticagrelor versus clopidogrel.

\section{Disclosure}

The authors report no conflicts of interest in this work. 


\section{References}

1. Lloyd-Jones D, Adams RJ, Brown TM, et al; American Heart Association Statistics Committee and Stroke Statistics Subcommittee. Executive summary: Heart disease and stroke statistics - 2010 update: A report from the American Heart Association. Circulation. 2010;121(7):948-954.

2. Furie B, Furie BC. Mechanisms of thrombus formation. NEngl J Med. 2008;359(9):938-949.

3. Rivera J, Lozano ML, Navarro-Núñez L, Vicente V. Platelet receptors and signaling in the dynamics of thrombus formation. Haematologica. 2009;94(5):700-711.

4. Anderson JL, Adams CD, Antman EM, et al; American College of Cardiology; American Heart Association Task Force on Practice Guidelines (Writing Committee to Revise the 2002 Guidelines for the Management of Patients With Unstable Angina/Non ST-Elevation Myocardial Infarction); American College of Emergency Physicians; Society for Cardiovascular Angiography and Interventions; Society of Thoracic Surgeons; American Association of Cardiovascular and Pulmonary Rehabilitation; Society for Academic Emergency Medicine. ACC/AHA 2007 guidelines for the management of patients with unstable angina/non ST-elevation myocardial infarction: a report of the American College of Cardiology/American Heart Association Task Force on Practice Guidelines (Writing Committee to Revise the 2002 Guidelines for the Management of Patients With Unstable Angina/Non ST-Elevation Myocardial Infarction): developed in collaboration with the American College of Emergency Physicians, the Society for Cardiovascular Angiography and Interventions, and the Society of Thoracic Surgeons: endorsed by the American Association of Cardiovascular and Pulmonary Rehabilitation and the Society for Academic Emergency Medicine. Circulation. 2007;116(7):e148-e304.

5. Bassand JP, Hamm CW, Ardissino D, et al; Task Force for Diagnosis and Treatment of Non-ST-Segment Elevation Acute Coronary Syndromes of European Society of Cardiology. Guidelines for the diagnosis and treatment of non-ST-segment elevation acute coronary syndromes. Eur Heart J. 2007;28(13):1598-1660.

6. ISIS-2 (Second International Study of Infarct Survival) Collaborative Group. Randomised trial of intravenous streptokinase, oral aspirin, both, or neither among 17,187 cases of suspected acute myocardial infarction. Lancet. 1988;2(8607):349-360.

7. Yusuf S, Zhao F, Mehta SR, Chrolavicius S, Tognoni G, Fox KK; Clopidogrel in Unstable Angina to Prevent Recurrent Events Trial Investigators. Effects of clopidogrel in addition to aspirin in patients with acute coronary syndromes without ST-segment elevation. $N$ Engl J Med. 2001;345(7):494-502.

8. Wiviott SD, Trenk D, Frelinger AL, et al; PRINCIPLE-TIMI 44 Investigators. Prasugrel compared with high loading- and maintenance-dose clopidogrel in patients with planned percutaneous coronary intervention: The Prasugrel in Comparison to Clopidogrel for Inhibition of Platelet Activation and Aggregation-Thrombolysis in Myocardial Infarction 44 trial. Circulation. 2007;116(25):2923-2932.

9. Wiviott SD, Braunwald E, McCabe CH, et al; for the TRITON-TIMI 38 Investigators. Prasugrel versus clopidogrel in patients with acute coronary syndromes. $N$ Engl J Med. 2007;357(20):2001-2015.

10. Mehta S. The Clopidogrel Optimal Loading Dose Usage to Reduce Recurrent Events/Optimal Antiplatelet Strategy for Interventions (CURRENT OASIS-7). Presented at the European Society of Cardiology 2009, Barcelona, Spain. Available at: http://cardiobrief.org/2009/08/30/ esc-high-dose-clopidogrel-aids-pci-for-acs-current-oasis-7/. Accessed Aug 05, 2010.

11. Fox KA, Mehta SR, Peters R, et al; Clopidogrel in Unstable angina to prevent Recurrent ischemic Events trial. Benefits and risks of the combination of clopidogrel and aspirin in patients undergoing surgical revascularization for non-ST-elevation acute coronary syndrome: The Clopidogrel in Unstable angina to prevent Recurrent ischemic Events (CURE) trial. Circulation. 2004;110(10):1202-1208.

12. Hongo RH, Ley J, Dick SE, Yee RR. The effect of clopidogrel in combination with aspirin when given before coronary artery bypass grafting. J Am Coll Cardiol. 2002;40(2):231-237.
13. Gurbel PA, Bliden KP, Hiatt BL, O’Connor CM. Clopidogrel for coronary stenting: Response variability, drug resistance, and the effect of pretreatment platelet reactivity. Circulation. 2003;107(23):2908-2913.

14. Matetzky S, Shenkman B, Guetta V, et al. Clopidogrel resistance is associated with increased risk of recurrent atherothrombotic events in patients with acute myocardial infarction. Circulation. 2004;109(25): 3171-3175.

15. Mehran R, Pocock SJ, Stone GW, et al. Associations of major bleeding and myocardial infarction with the incidence and timing of mortality in patients presenting with non-ST-elevation acute coronary syndromes: A risk model from the ACUITY trial. Eur Heart J. 2009;30(12): 1457-1466.

16. Eikelboom JW, Mehta SR, Anand SS, Xie C, Fox KAA, Yusuf S. Adverse impact of bleeding on prognosis in patients with acute coronary syndromes. Circulation. 2006;114(8):774-782.

17. Manoukian SV, Feit F, Mehran R, et al. Impact of major bleeding on 30-day mortality and clinical outcomes in patients with acute coronary syndromes: An analysis from the ACUITY Trial. J Am Coll Cardiol. 2007;49(12):1362-1368.

18. Rao SV, Eikelboom JA, Granger CB, Harrington RA, Califf RM, Bassand J-P. Bleeding and blood transfusion issues in patients with non-ST-segment elevation acute coronary syndromes. Eur Heart J. 2007;28(10):1193-1204.

19. Van Giezen JJ, Nilsson L, Berntsson P, et al. Ticagrelor binds to human P2Y(12) independently from ADP but antagonizes ADP-induced receptor signaling and platelet aggregation. J Thromb Haemost. 2009;7(9):1556-1565.

20. Husted S, Emanuelsson H, Heptinstall S, Sandset PM, Wickens M, Peters G. Pharmacodynamics, pharmacokinetics, and safety of the oral reversible P2Y12 antagonist AZD6140 with aspirin in patients with atherosclerosis: A double-blind comparison to clopidogrel with aspirin. Eur Heart J. 2006;27(9):1038-1047.

21. Peters G, Robbie G. Single-dose pharmacokinetics and pharmacodynamics of AZD6140 - an oral reversible ADP receptor antagonist. Haematologica. 2004;989 Suppl 7:14.

22. Cannon CP, Husted S, Harrington RA, et al. Safety, tolerability, and initial efficacy of AZD6140, the first reversible oraladenosine diphosphate receptor antagonist, compared with clopidogrel, in patients with non-ST-segment elevation acute coronary syndrome: Primary results of the DISPERSE-2 trial. J Am Coll Cardiol. 2007;50(19): 1844-1851.

23. Gurbel PA, Bliden KP, Butler K, et al. Randomized double-blind assessment of the ONSET and OFFSET of the antiplatelet effects of ticagrelor versus clopidogrel in patients with stable coronary artery disease: The ONSET/OFFSET study. Circulation. 2009;120(25):2577-2585.

24. Gurbel PA, Bliden KP, Butler K, et al. Response to ticagrelor in clopidogrel nonresponders and responders and effect of switching therapies: The RESPOND study. Circulation. 2010;121(10):1188-1199.

25. Wallentin L, Becker RC, Budaj A, et al; PLATO Investigators. Ticagrelor versus clopidogrel in patients with acute coronary syndromes. $N$ Engl J Med. 2009;361(11):1045-1057.

26. James S, Akerblom A, Cannon CP, et al. Comparison of ticagrelor, the first reversible oral $\mathrm{P} 2 \mathrm{Y}(12)$ receptor antagonist, with clopidogrel in patients with acute coronary syndromes: Rationale, design, and baseline characteristics of the PLATelet inhibition and patient Outcomes (PLATO) trial. Am Heart J. 2009;157(4):599-605.

27. Cannon CP, Harrington RA, James S, et al; PLATelet inhibition and patient Outcomes Investigators. Comparison of ticagrelor with clopidogrel in patients with a planned invasive strategy for acute coronary syndromes (PLATO): a randomised double-blind study. Lancet. 2010; 375(9711):283-293.

28. Steg PG, Becker RC, Cannon CP, et al. Comparison of ticagrelor, the first reversible oral P2Y12 receptor antagonist, with clopidogrel in patients with acute coronary syndromes: Results from the PLATelet inhibition and patient Outcomes (PLATO) trial. Circulation. 2009; 120(21):2153-2154. 
29. Storey RF, Bliden KP, Patil SB, et al; ONSET/OFFSET Investigators. Incidence of dyspnea and assessment of cardiac and pulmonary function in patients with stable coronary artery disease receiving ticagrelor, clopidogrel, or placebo in the ONSET/OFFSET study. J Am Coll Cardiol. 2010;56(3):185-193.

30. The Fifth Organization to Assess Strategies in Acute Ischemic Syndromes Investigators. Comparison of fondaparinux and enoxaparin in acute coronary syndromes. $N$ Engl J Med. 2006;354(14):1464-1476.
31. Stone GW, Witzenbichler B, Guagliumi G, et al; for the HORIZONS-AMI Trial Investigators. Bivalirudin during primary PCI in acute myocardial infarction. N Engl J Med. 2008;358(21):2218-2230.

32. Stone GW. Ticagrelor in ACS: Redefining a new standard of care? Lancet. 2010;375(9711):263-265.

\section{Publish your work in this journal}

Vascular Health and Risk Management is an international, peerreviewed journal of therapeutics and risk management, focusing on concise rapid reporting of clinical studies on the processes involved in the maintenance of vascular health; the monitoring, prevention and treatment of vascular disease and its sequelae; and the involvement of metabolic disorders, particularly diabetes. This journal is indexed on PubMed Central and MedLine. The manuscript management system is completely online and includes a very quick and fair peer-review system, which is all easy to use. Visit http://www.dovepress.com/ testimonials.php to read real quotes from published authors.

Submit your manuscript here: http://www.dovepress.com/vascular-health-and-risk-management-journal 